\title{
An Investigation on the Thermal Characteristics of a Single-Effect Absorption Chiller Subjected to the Input Steam Fluctuation
}

\author{
Taninrat Vittayakaisin $^{\mathrm{a}}$ and Chittin Tangthieng ${ }^{\mathrm{b}}$ \\ Department of Mechanical Engineering, Faculty of Engineering, Chulalongkorn University, Phayathai Rd., \\ Wangmai, Patumwan, Bangkok 10330, Thailand \\ E-mail: apatchai_hotman@hotmail.com, bqed690@yahoo.com (Corresponding author)
}

\begin{abstract}
This paper presents an investigation on the thermal characteristics of a singleeffect absorption chiller subjected to the input steam fluctuation for an air-conditioning purpose. The absorption chiller driven by waste steam is utilized with the total capacity of 270 tons. The analyzed data are obtained by the field measurement. The results indicate that most measuring parameters appear to be nearly constant with time whereas the chilled water outlet temperature and the cooling water outlet temperature appear to have a similar wave characteristic to the mass flow rate of the input steam. The regression analysis is performed in order to obtain the sine function of these three parameters. The lagging behavior of the cooling load and the rejected heat rate behind the input heat rate from waste steam is observed due to the thermal inertia of the absorption chiller. The energy analysis shows that the average cooling load, rejected heat rate and input heat rate from waste steam is $345.78 \mathrm{~kW}, 1033.80 \mathrm{~kW}$, and $572.88 \mathrm{~kW}$, respectively. The coefficient of performance of the absorption chiller has a high fluctuation from 0.296 to 1.524 with an average value of 0.754 , resulted from the fluctuation of the mass flow rate of the input steam. The result indicates that the average value of the residual heat rate is $170.14 \mathrm{~kW}$, which is approximately 10 percent of the total input heat.
\end{abstract}

Keywords: Thermal characteristics, absorption chiller, field measurement, energy analysis.

ENGINEERING JOURNAL Volume 18 Issue 2

Received 11 June 2013

Accepted 15 October 2013

Published 18 April 2014

Online at http://www.engj.org/

DOI:10.4186/ej.2014.18.2.55 


\section{Introduction}

Over the last few decades, the energy efficiency becomes one of the most interesting topics due to the depletion of fossil fuel. Implementation of heating processes in most industries usually leads to a large amount of waste heat released to the environment. Therefore, it is beneficial to utilize the heat recovery devices to save the energy cost and protect the environment. An absorption chiller is also one of the heat recovery devices used to recover waste heat back to provide the cooling effect. In general, the thermal energy used to drive an absorption chiller may originate from many sources such as direct-fired burners [1, $2]$, steam [3, 4], flue gas [5, 6] or hot water [7, 8]. Because an absorption chiller is a heat-driven device, theoretically, the coefficient of performance (COP) of an absorption chiller is relatively low compared to that of a conventional electric one [9]. It is suggested that the heat source for an absorption chiller should be abundant and inexpensive, including the solar or geothermal heating $[10,11]$. As a result, the energy analysis of the absorption refrigeration system [12-14] and the economic assessment of the implementation of the absorption chiller $[15,16]$ should be considered.

Most of the absorption-chiller analysis is performed under the steady state condition since the input heat rate and the cooling load are assumed constant. However, the absorption chiller driven by the waste steam may encounter a difficulty to control the input steam mass flow rate. In the case under our consideration, the pressure of the waste steam in the main flow is highly fluctuated. In general, the amount of the input steam mass flow rate is controlled by a control valve [17], which will be modulated according to how an actual chilled water temperature deviates from a set point one. As a result, the fluctuation of the chilled water outlet temperature is also observed. Thus, the focus of this research is to investigate the effect of the input steam fluctuation on the thermal characteristics of the absorption chiller. An energy analysis of a single-effect absorption chiller driven based on the input steam fluctuation is performed. The data obtained by the field measurement are analyzed by using the sinusoidal regression since the wave functions of some variables are observed. Thereafter, the thermal characteristics of the absorption chiller are investigated, including the calculation of the cooling load, the rejected heat rate, the input heat rate from waste steam, the coefficient of performance and the residual heat rate.

\section{Measuring devices and methodology}

The single-effect $\mathrm{LiBr}-\mathrm{H}_{2} \mathrm{O}$ absorption chiller in the study is used to supply chilled water to three airconditioning rooms in an office building. These three rooms are the control room, ISDL room and laboratory. The heat source for the absorption chiller comes from waste steam produced by a nearby petrochemical plant as shown in Fig. 1.

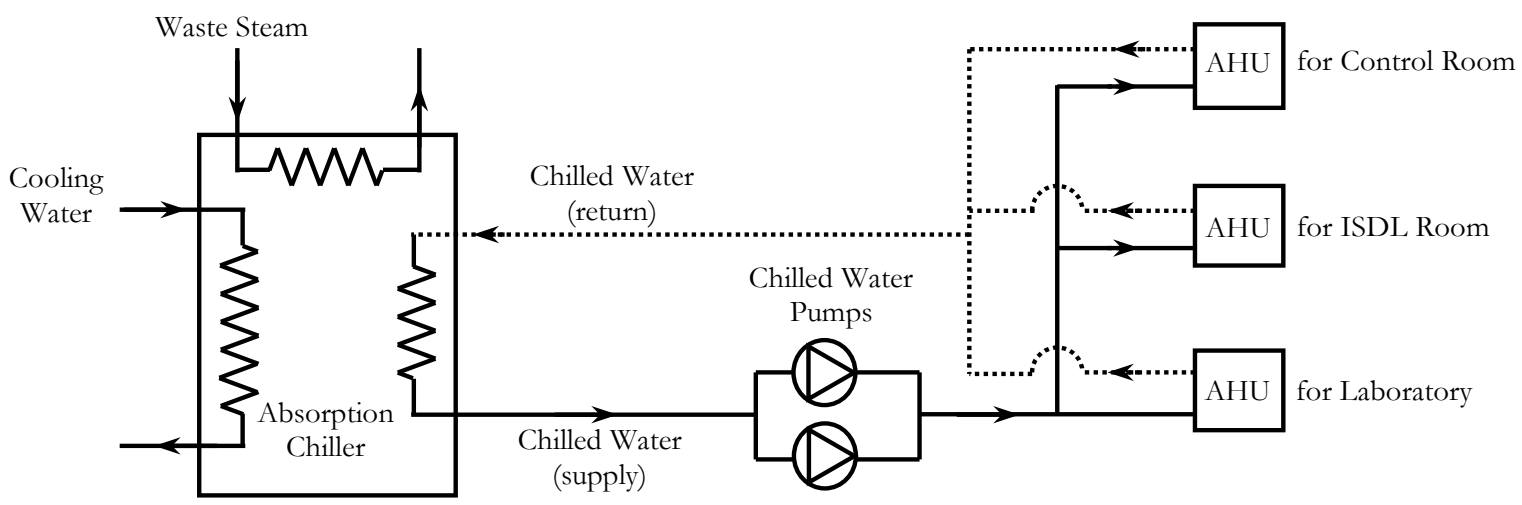

Fig. 1. Schematic diagram of the absorption chiller under consideration.

The cooling capacity of the $\mathrm{LiBr}-\mathrm{H}_{2} \mathrm{O}$ absorption chiller is 270 tons of refrigeration. A $37-\mathrm{kW}$ chilled water pump with a spare is used to supply chiller water to all three air handling units (AHUs). By applying a control volume over the absorption refrigeration system, the theoretical energy balance of this can be depicted in Fig. 2. It should be noted that the rejected heat rate of the absorption chiller comes from two sources: the exothermic reaction by dissolving more water in weak $\mathrm{LiBr}-\mathrm{H}_{2} \mathrm{O}$ solution at the absorber and the latent heat of condensation of water at the condenser. On the other hand, the waste steam is used as a 
heat source to separate water from the strong $\mathrm{LiBr}-\mathrm{H}_{2} \mathrm{O}$ solution at the generator. The input power of the absorption chiller includes the pump power for the $\mathrm{LiBr}-\mathrm{H}_{2} \mathrm{O}$ solution and the power for the control unit.

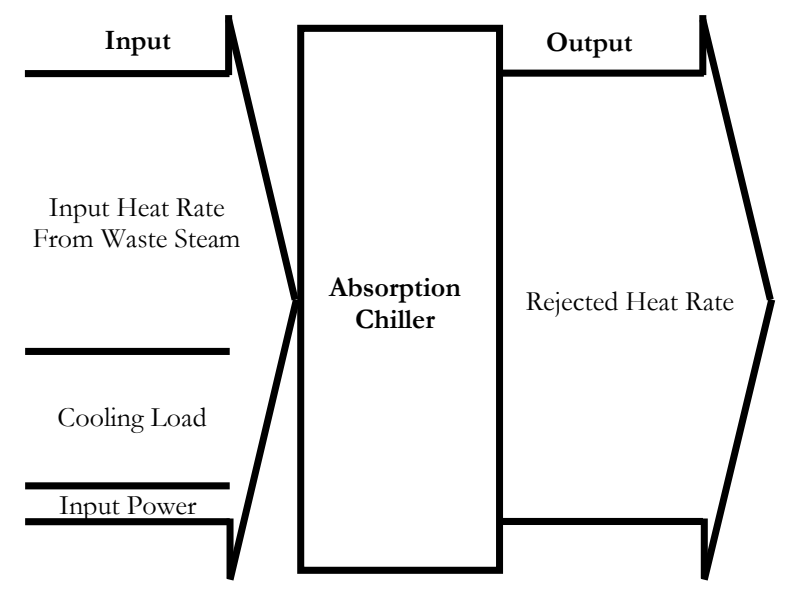

Fig. 2. Theoretical energy balance of the absorption refrigeration system.

For the field measurement, the measuring devices and methodology is summarized in Table 1. It is expected that the input electric power of the absorption chiller should be nearly constant over a period of time since this power is mainly used for operating an internal pump of the absorption chiller. Likewise, the volume flow rates of chilled water and cooling water should be nearly constant due to the steady-state operation of the chilled water and cooling water pumps without any sudden change of the piping system and without a variable speed drive control. Therefore, the measuring period will be four days for every 15 minutes in order to obtain enough accuracy to determine the average values of these three variables. On the other hand, the chilled water inlet and outlet temperatures, the cooling water inlet and outlet temperatures, and the mass flow rate of the input steam may exhibit the variation during a short period of time. The measuring period is then 15 minutes for every 30 seconds.

Table 1. The measuring devices and methodology.

\begin{tabular}{|c|c|c|c|c|}
\hline Audit item & Symbol & Measuring device & Methodology & Accuracy \\
\hline $\begin{array}{l}\text { 1. Input electric power of } \\
\text { the absorption chiller }\end{array}$ & $\dot{W}_{A C}$ & $\begin{array}{c}\text { Power meter with a } \\
\text { data logger }\end{array}$ & $\begin{array}{l}\text { Record data for every } \\
15 \text { minutes in } 4 \text { days }\end{array}$ & $\pm 1 \%$ \\
\hline $\begin{array}{l}\text { 2. Volume flow rate of } \\
\text { chilled water }\end{array}$ & $\mathrm{FL}_{\mathrm{CHW}}$ & $\begin{array}{l}\text { Ultrasonic } \\
\text { flowmeter }\end{array}$ & $\begin{array}{l}\text { Record data for every } \\
15 \text { minutes in } 4 \text { days }\end{array}$ & $\pm 2 \%$ \\
\hline $\begin{array}{l}\text { 3. Volume flow rate of } \\
\text { cooling water }\end{array}$ & $\mathrm{FL}_{\mathrm{CLW}}$ & $\begin{array}{l}\text { Ultrasonic } \\
\text { flowmeter }\end{array}$ & $\begin{array}{l}\text { Record data for every } \\
15 \text { minutes in } 4 \text { days }\end{array}$ & $\pm 2 \%$ \\
\hline $\begin{array}{l}\text { 4. Chilled water inlet and } \\
\text { outlet temperatures }\end{array}$ & $\begin{array}{l}\mathrm{T}_{\mathrm{CHW}, \text { in }}, \\
\mathrm{T}_{\mathrm{CHW}, \text { out }}\end{array}$ & $\begin{array}{c}\text { Thermocouple } \\
\text { probes }\end{array}$ & $\begin{array}{c}\text { Record data for every } \\
30 \text { seconds in } 15 \\
\text { minutes }\end{array}$ & $\pm 0.1^{\circ} \mathrm{C}$ \\
\hline $\begin{array}{l}\text { 5. Cooling water inlet and } \\
\text { outlet temperatures }\end{array}$ & $\begin{array}{l}\mathrm{T}_{\mathrm{CLW}, \text { in }} \\
\mathrm{T}_{\text {CLW,out }}\end{array}$ & $\begin{array}{c}\text { Thermocouple } \\
\text { probes }\end{array}$ & $\begin{array}{c}\text { Record data for every } \\
30 \text { seconds in } 15 \\
\text { minutes }\end{array}$ & $\pm 0.1^{\circ} \mathrm{C}$ \\
\hline $\begin{array}{l}\text { 6. Mass flow rate of the } \\
\text { input steam }\end{array}$ & $\dot{m}_{S T}$ & $\begin{array}{l}\text { Orifice plate with } \\
\text { pressure transmitter }\end{array}$ & $\begin{array}{c}\text { Record data for every } \\
30 \text { seconds in } 15 \\
\text { minutes }\end{array}$ & $\pm 2 \%$ \\
\hline
\end{tabular}

Most of the measuring devices are portable, except the steam flow meter which is a fixed measuring device used for the plant. The power meter range includes both three-phase and single-phase devices with a maximum current and voltage up to 6,500 A and $600 \mathrm{~V}$, respectively. For measuring the steam mass flow rate, the differential pressure across the orifice plate will be first converted to the 4-20 mA DC signal by the 
pressure transmitter and eventually converted to the mass flow rate by the control unit. The ultrasonic flowmeter is applicable to homogeneous liquid flow with low solid content. The range of the flowmeter is between 0.2 to $12 \mathrm{~m} / \mathrm{s}$. For the chilled water and cooling water temperature measurement, the type-K thermocouples are used with metallic probes. In order to record temperature data, the liquid-in-glass thermometers must be removed from the thermowells and replaced by the thermocouple probes. It is noted that during the entire measurement period, the setting point temperature of the three designated rooms is $25^{\circ} \mathrm{C}$ as a control parameter.

\section{Results and Discussion}

\subsection{The Field Measurement Result}

Based on the measuring devices and methodology given by Table 1, the variations of the variables aforementioned in Table 1 with time are depicted in Figs. 3 to 7.

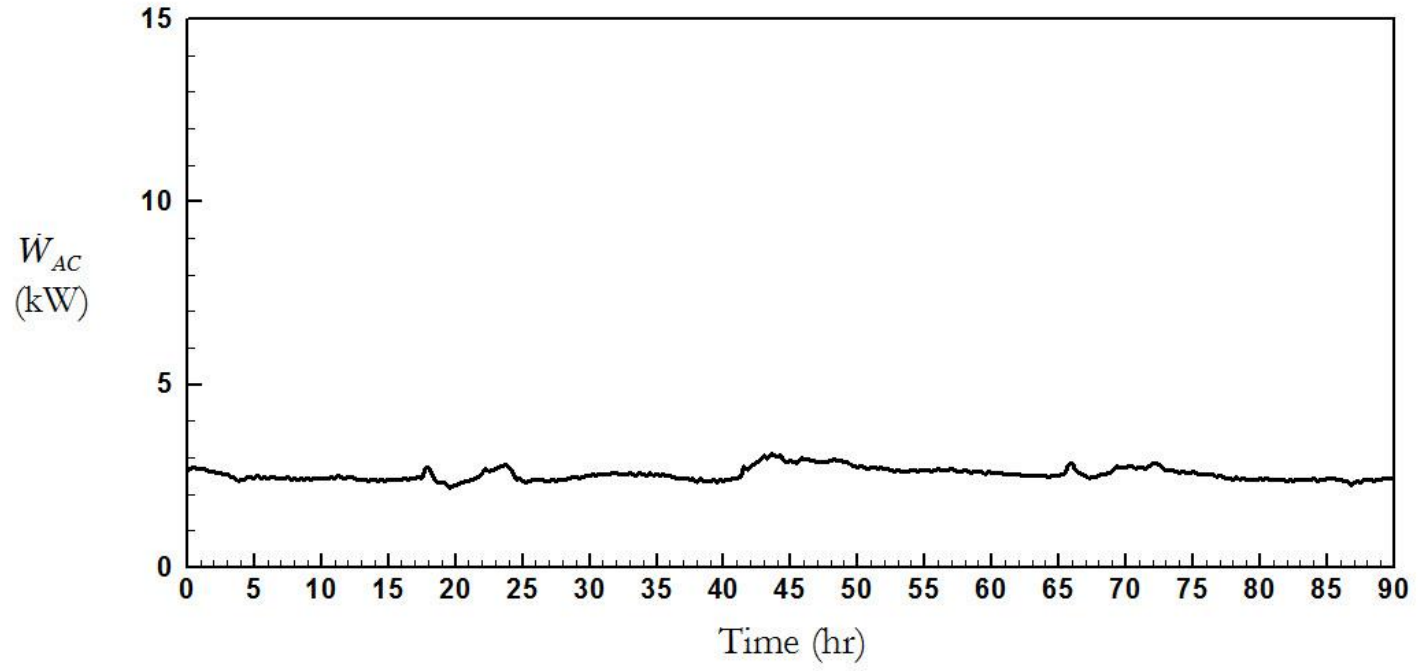

Fig. 3. Variation of the input electric power with time.

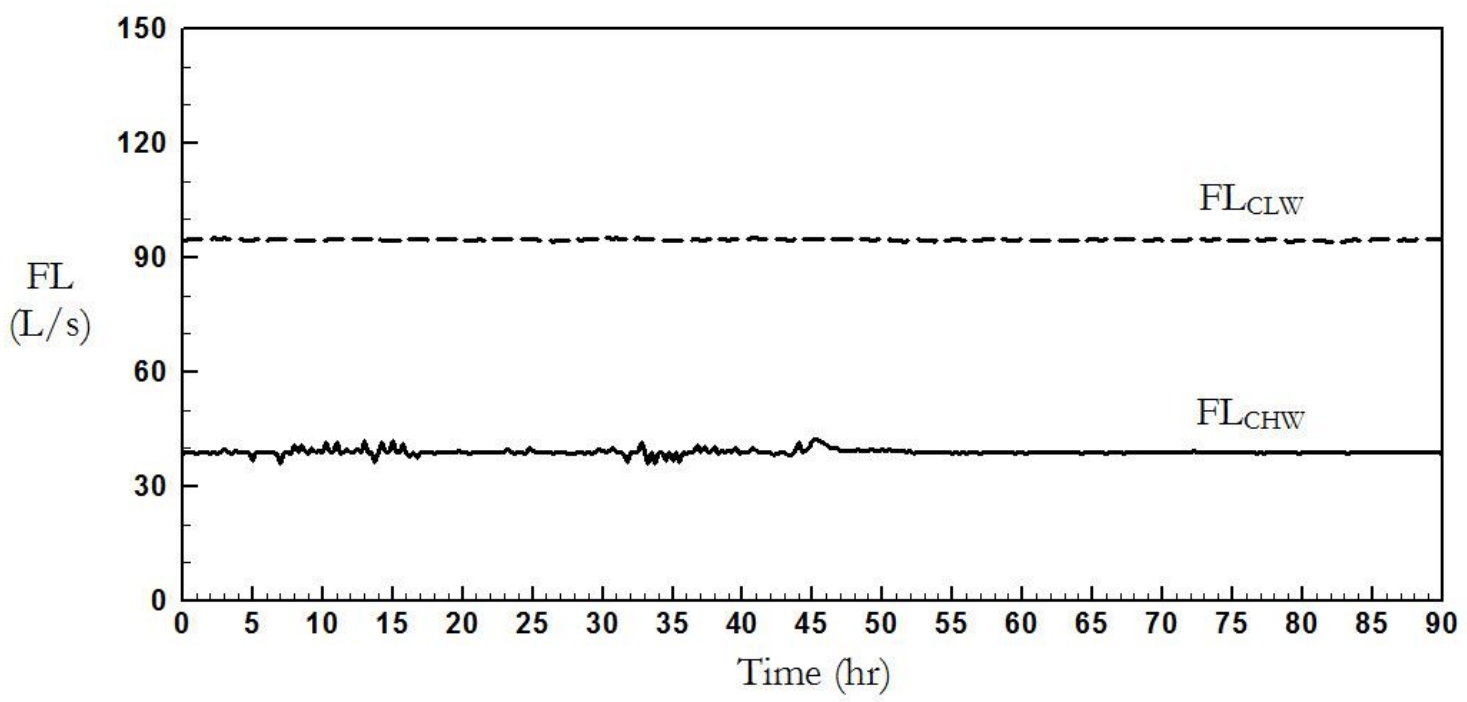

Fig. 4. Variations of the volume flow rates of the chilled water and cooling water with time. 


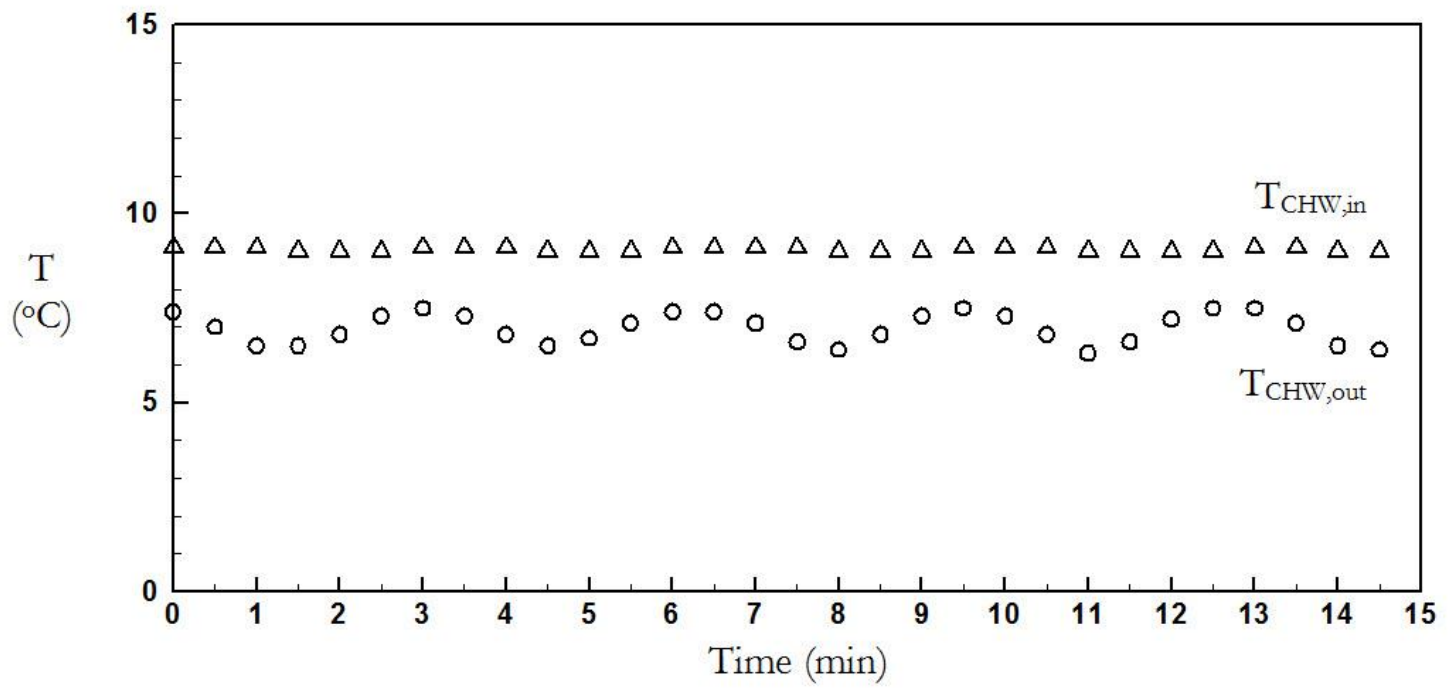

Fig. 5. Variations of the chilled water inlet and outlet temperatures with time.

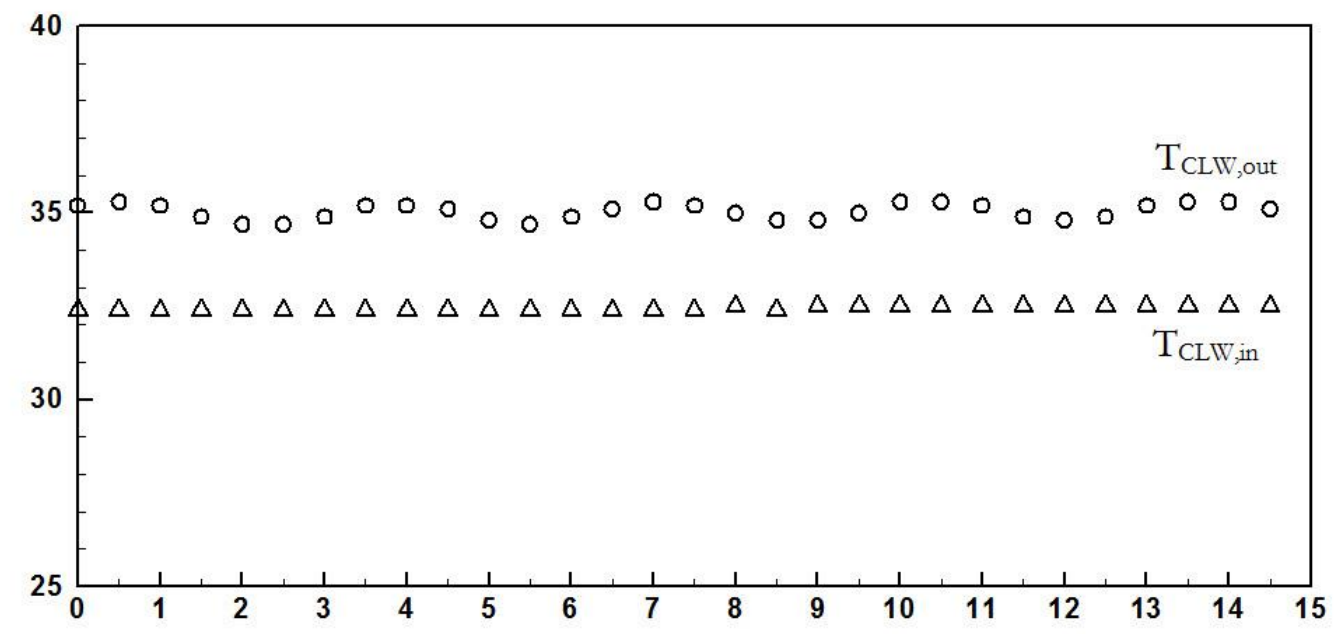

Fig. 6. Variations of the cooling water inlet and outlet temperatures with time.

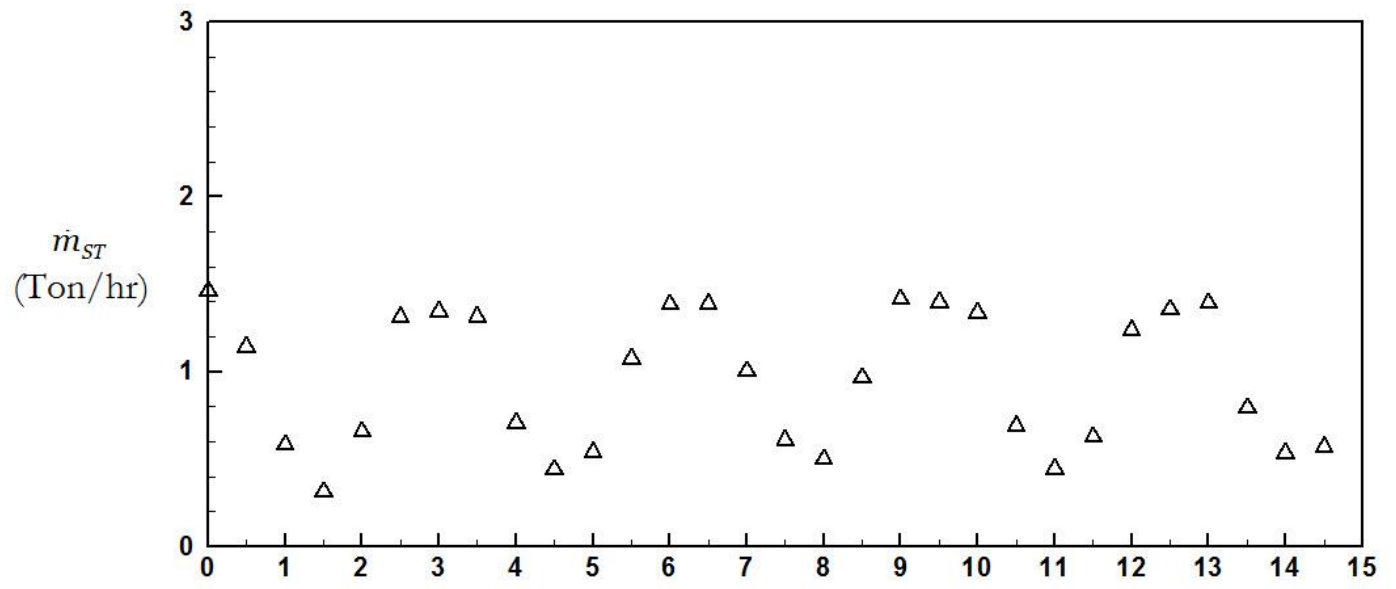

Fig. 7. Variation of the mass flow rate of the input steam with time.

It can be seen that $\dot{W}_{A C}, \mathrm{FL}_{\mathrm{CHW}}$ and $\mathrm{FL}_{\mathrm{CLW}}$ are nearly constant with time as expected. In addition,

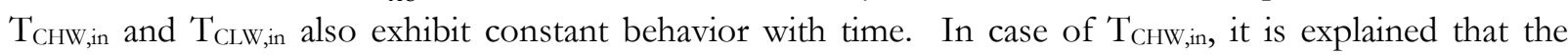


cooling load of the chiller does not have much change in a short period of time, leading to a nearly constant value of $T_{C H W, i n}$. In case of $T_{C L W, \text { in }}$, it does not have much change because the cooling water is supplied from the main cooling tower of the plant. As a result, it is reasonable to use a simple average over the entire period of time as an approximation of these five variables. The results are given in Table 2.

Table 2. The average values of the input electric power, the volume flow rate of the chilled water and cooling water, the chilled water and cooling water inlet temperatures.

\begin{tabular}{lr}
\hline Variables & Average Values \\
\hline$\dot{W}_{A C}$ & $2.53 \mathrm{~kW}$ \\
$\mathrm{FL}_{\mathrm{CHW}}$ & $39.03 \mathrm{~L} / \mathrm{s}$ \\
$\mathrm{FL}_{\mathrm{CLW}}$ & $94.73 \mathrm{~L} / \mathrm{s}$ \\
$\mathrm{T}_{\mathrm{CHW}, \text { in }}$ & $9.05^{\circ} \mathrm{C}$ \\
$\mathrm{T}_{\mathrm{CLWW}, \text { in }}$ & $32.44{ }^{\circ} \mathrm{C}$ \\
\hline
\end{tabular}

On the other hand, it is observed from Figs. 5 to 7 that the values of $\mathrm{T}_{\mathrm{CHW}, \text { out }}, \mathrm{T}_{\mathrm{CLW}, \text { out }}$ and $\dot{m}_{S T}$ exhibit the sinusoidal behaviors with time. In order to determine the expression of these three variables with time, the regression analysis is required and explained in the next section.

\subsection{Regression Analysis}

The general form of the sine wave can be written as [18]:

$$
Y-\bar{Y}=A \sin \left(\frac{2 \pi}{\tau}(t-\varphi)\right)
$$

where $A$ is the amplitude, $\tau$ is the wave period, $\phi$ is the phase and $\bar{Y}$ is the arithmetic mean of the dependent variables, i.e., $\mathrm{T}_{\mathrm{CHW}, \text { out, }} \mathrm{T}_{\mathrm{CLW}, \text { out }}$ and $\dot{m}_{S T}$. To obtain the values of $A, \phi$ and $\tau$, the regression analysis is performed on the field measurement data. From the observation of Figs. 5 to 7, it should be noted that these three variables of $\mathrm{T}_{\mathrm{CHW}, \text { out }} \mathrm{T}_{\mathrm{CLW}, \text { out }}$ and $\dot{m}_{S T}$ exhibit the same wave period, but different amplitude and different phase. Therefore, the assumption of identical values of $\tau$ for these three variables is made for the regression analysis. As a result, the coefficients for the sine function of each dependent variable are given in Table 3. In addition, the coefficients of determination or $\mathrm{R}^{2}$ of the regression analysis are provided.

Table 3. The coefficients for the sine function and the coefficients of determination from regression analysis for the related variables.

\begin{tabular}{cccccc}
\hline \multirow{2}{*}{$Y$} & $\bar{Y}$ & \multicolumn{3}{c}{ Coefficients } & \multirow{2}{*}{$\mathbf{R}^{2}$} \\
\cline { 3 - 5 } & & $\boldsymbol{A}$ & $\boldsymbol{\tau}$ & $\boldsymbol{\phi}$ & \\
\hline $\mathrm{T}_{\mathrm{CHW}, \text { out }}$ & $6.97^{\circ} \mathrm{C}$ & $0.55^{\circ} \mathrm{C}$ & $191.6 \mathrm{~s}$ & $130.5 \mathrm{~s}$ & 0.93 \\
$\mathrm{~T}_{\mathrm{CLW}, \text { out }}$ & $35.04^{\circ} \mathrm{C}$ & $0.28^{\circ} \mathrm{C}$ & $191.6 \mathrm{~s}$ & $187.5 \mathrm{~s}$ & 0.87 \\
$\dot{m}_{S T}$ & $0.95 \mathrm{Ton} / \mathrm{hr}$ & $0.51 \mathrm{Ton} / \mathrm{hr}$ & $191.6 \mathrm{~s}$ & $153.0 \mathrm{~s}$ & 0.88 \\
\hline
\end{tabular}

The comparison between the field measurement data and the estimated sine function of $\mathrm{T}_{\mathrm{CHW}, \text { out }}, \mathrm{T}_{\mathrm{CLW}, \text { out }}$ and $\dot{m}_{S T}$ are depicted in Figs. 8 to 10. 


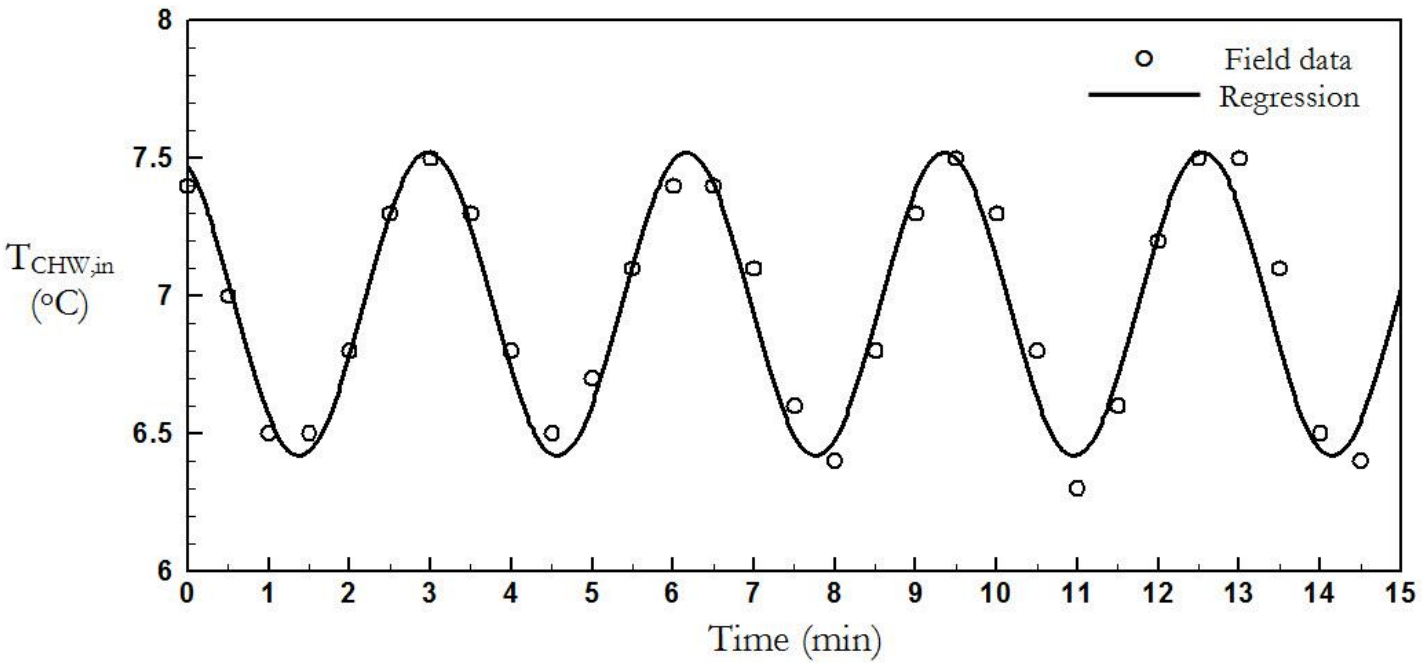

Fig. 8. Comparison between the field measurement data and the estimated sine function of the chilled water outlet temperature.

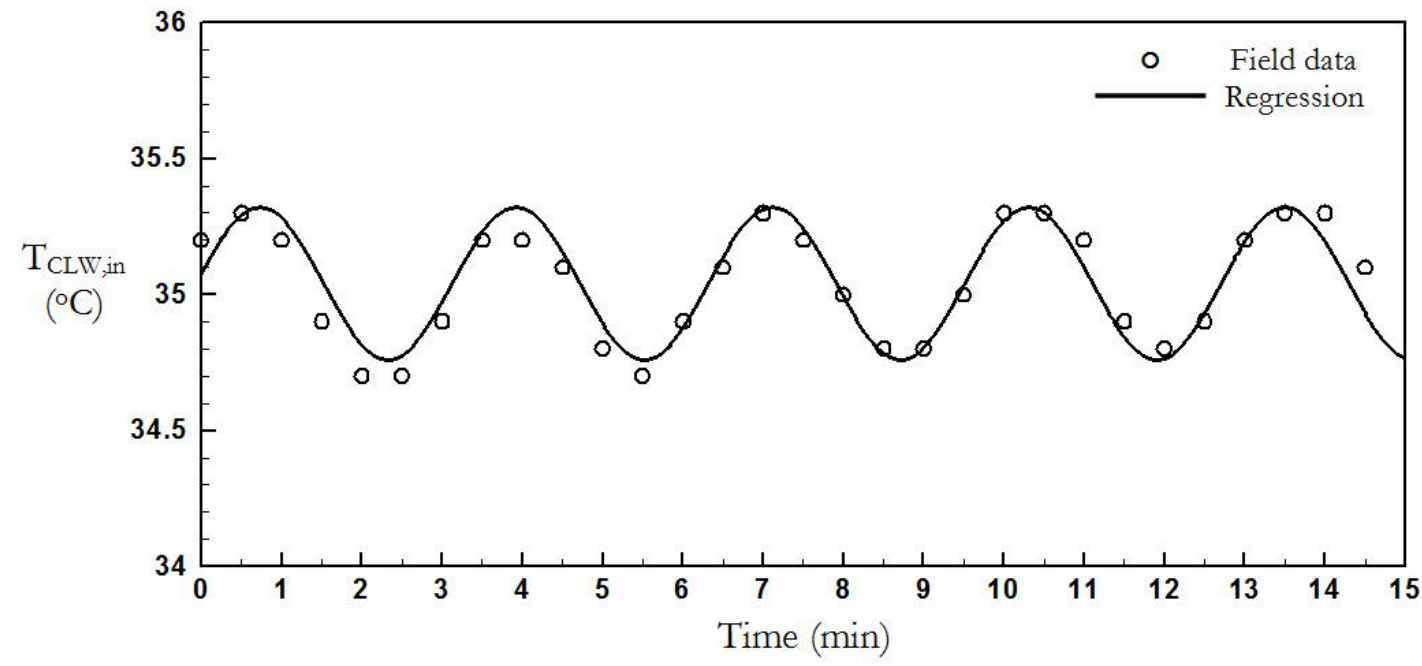

Fig. 9. Comparison between the field measurement data and the estimated sine function of the cooling water outlet temperature.

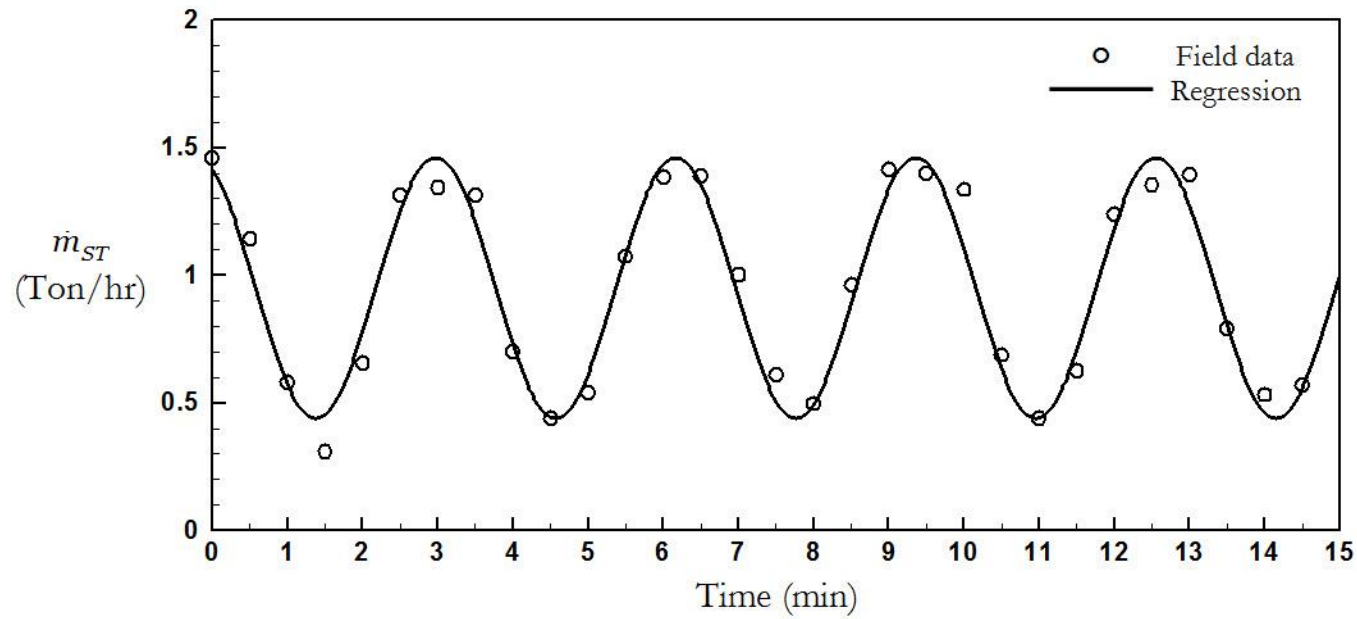

Fig. 10. Comparison between the field measurement data and the estimated sine function of the mass flow rate of the input steam. 


\subsection{Energy Analysis}

The analysis of the performance of the absorption chiller is based on the field data measurement in Section 3.1. The supplementary data such as the properties of steam and water are given in [19]. First, the cooling load of the absorption chiller or $\dot{Q}_{C L}$ can be calculated by

$$
\dot{Q}_{C L}=\dot{m}_{C H W} C_{P, C H W}\left(T_{C H W, \text { in }}-T_{C H W, \text { out }}\right)
$$

Since FL $\mathrm{F}_{\mathrm{CHW}}$ is given by Table $2, \dot{m}_{C H W}$ or the mass flow rate of the chilled water is equal to $39.03 \mathrm{~kg} / \mathrm{s}$ by taking the density of the chilled water to be $1 \mathrm{~kg} / \mathrm{L}$. The average value of $\mathrm{T}_{\mathrm{CHW}}$, in is given by Table 2 whereas $T_{\mathrm{CHW}, \text { out }}$ is expressed by Eq. (1) with the coefficients provided in Table 3 . The value of $\mathrm{C}_{\mathrm{P}, \mathrm{CHW}}$ or the specific heat of the chilled water is given by $4.208 \mathrm{~kJ} / \mathrm{kg}-\mathrm{K}$.

The rejected heat rate from the chiller or $\dot{Q}_{R E J}$ is given by

$$
\dot{Q}_{R E J}=\dot{m}_{C L W} C_{P, C L W}\left(T_{C L W, \text { out }}-T_{C L W, \text { in }}\right)
$$

Based on the value of FLCLW given by Table 2, the value of $\dot{m}_{C L W}$ is equal to $94.73 \mathrm{~kg} / \mathrm{s}$. The average value of $\mathrm{T}_{\mathrm{CLW} \text {, in }}$ is given by Table 2 whereas $\mathrm{T}_{\text {CLW, out }}$ is expressed by Eq. (1) with the coefficients provided in Table 3. The value of $C_{P, C L W}$ or the specific heat of the cooling water is given by $4.180 \mathrm{~kJ} / \mathrm{kg}-\mathrm{K}$.

The input heat rate or $\dot{Q}_{S T}$ can be expressed as

$$
\dot{Q}_{S T}=\frac{\dot{m}_{S T} h_{f g, S T}}{3.6}
$$

$\dot{m}_{S T}$ is expressed by Eq. (1) with the coefficients provided in Table 3. $\mathrm{h}_{\mathrm{fg}, S T}$ is the enthalpy of vaporization of water is given by $2,190.7 \mathrm{~kJ} / \mathrm{kg}$ since the average steam pressure is $226.7 \mathrm{kPa}$. The variations of $\dot{Q}_{C L}, \dot{Q}_{R E J}$ and $\dot{Q}_{S T}$ with time are depicted in Fig. 11 .

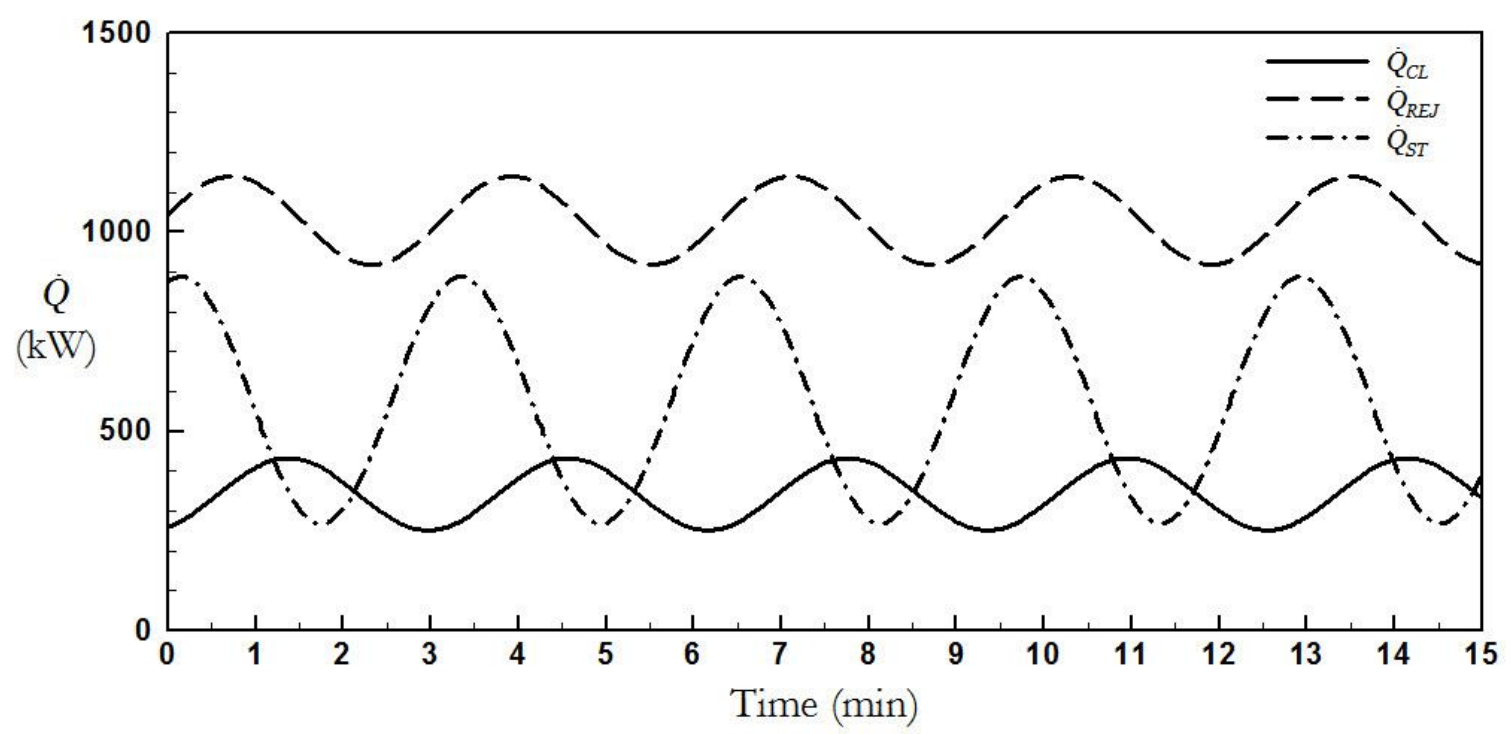

Fig. 11. Variations of the cooling load, the rejected heat rate, and the input heat rate with time.

To determine the coefficient of performance or COP of the absorption chiller, the average input power of the chiller or $\dot{W}_{A C}$ is provided in Table 2. As a result, COP can be expressed as

$$
C O P=\frac{\dot{Q}_{C L}}{\dot{W}_{A C}+\dot{Q}_{S T}}
$$

The variation of COP with time is depicted in Fig. 12. 


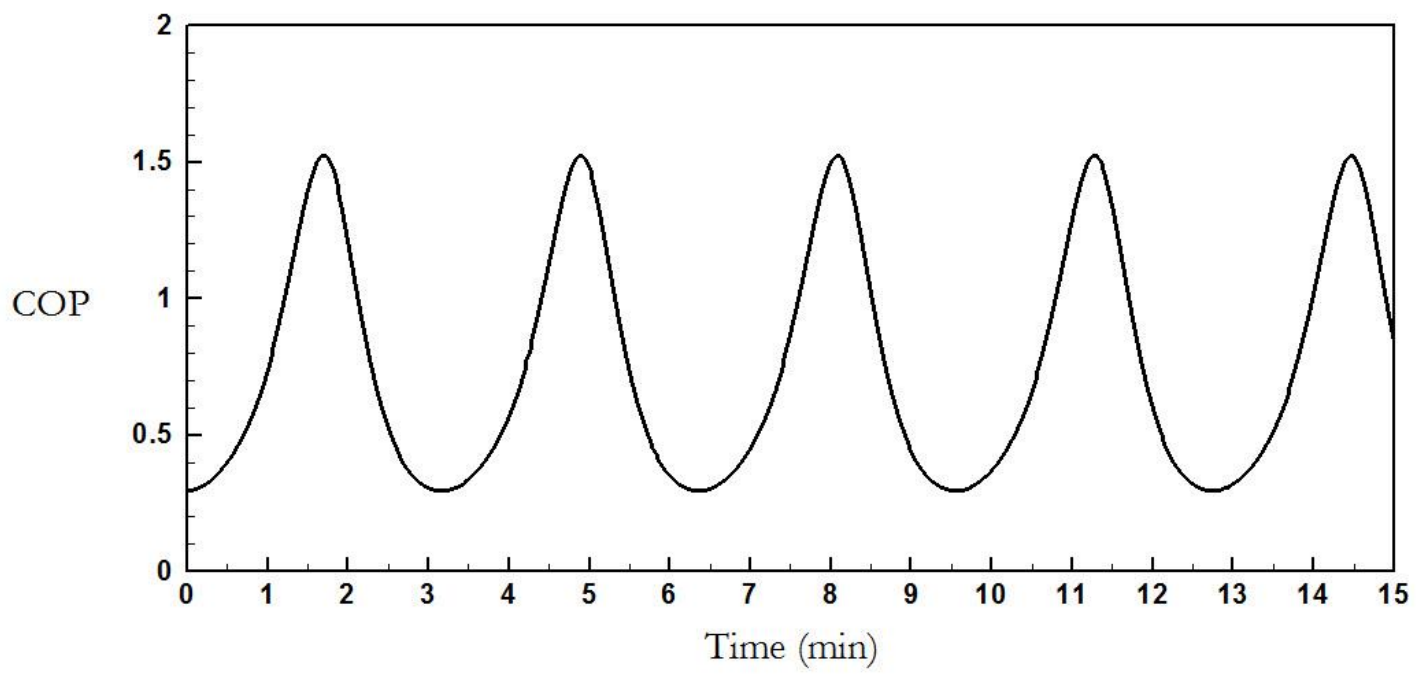

Fig. 12. Variation of the coefficient of performance of the absorption chiller with time.

It can be seen that $\dot{Q}_{C L}, \dot{Q}_{R E J}$ and $\dot{Q}_{S T}$ also exhibit the sinusoidal behaviors with different phases: $\dot{Q}_{C L}$ and $\dot{Q}_{R E J} \operatorname{lag} \dot{Q}_{S T}$. The average values of $\dot{Q}_{C L}, \dot{Q}_{R E J}$ and $\dot{Q}_{S T}$ are $345.9 \mathrm{~kW}, 1,033.9 \mathrm{~kW}$ and $572.9 \mathrm{~kW}$, respectively. The lagging behavior of $\dot{Q}_{C L}$ and $\dot{Q}_{R E J}$ may be caused by the thermal inertia of the absorption chiller, which cannot respond to the input heat from steam on time. It is also observed that at a certain time when $\dot{Q}_{S T}$ reaches the maximum point, the value of $\dot{Q}_{C L}$ is still low, leading to a relatively low value of COP shown in Fig. 12. In contrast, once $\dot{Q}_{S T}$ almost reaches the minimum point with a moderate value of $\dot{Q}_{C L}$, COP will reach the maximum value. Because $\dot{Q}_{S T}$ varies from $267.8 \mathrm{~kW}$ to $888.4 \mathrm{~kW}$, which is approximately increased by 3.3 times in magnitude, COP has a high fluctuation from 0.296 to 1.524 with an average value of 0.754 . In general, the value of $\mathrm{COP}$ of a single-effect absorption chiller is typically between 0.7 and $0.8[20,21]$. It is noted that since COP is highly fluctuated, the energy evaluation program of this absorption chiller must be carefully conducted with the recognition of the fluctuation behavior. Otherwise, the misinterpretation of either overrated or underrated performance of the chiller may occur.

The theoretical energy balance of the absorption refrigeration system is demonstrated in Fig. 2. However, for the actual absorption refrigeration system the energy balance can be performed by adding an additional term, i.e., the residual heat rate or $\dot{Q}_{R}$ as follows:

$$
\dot{Q}_{C L}+\dot{Q}_{S T}-\dot{Q}_{R E J}+\dot{W}_{A C}+\dot{Q}_{R}=0
$$

By substituting $\dot{Q}_{C L}, \dot{Q}_{R E J}, \dot{Q}_{S T}$ and $\dot{W}_{A C}$ from Eqs. (2) to (4) and Table 2, respectively, into Eq. (6), the behavior of $\dot{Q}_{R}$ as s function of time is depicted in Fig. 13. 


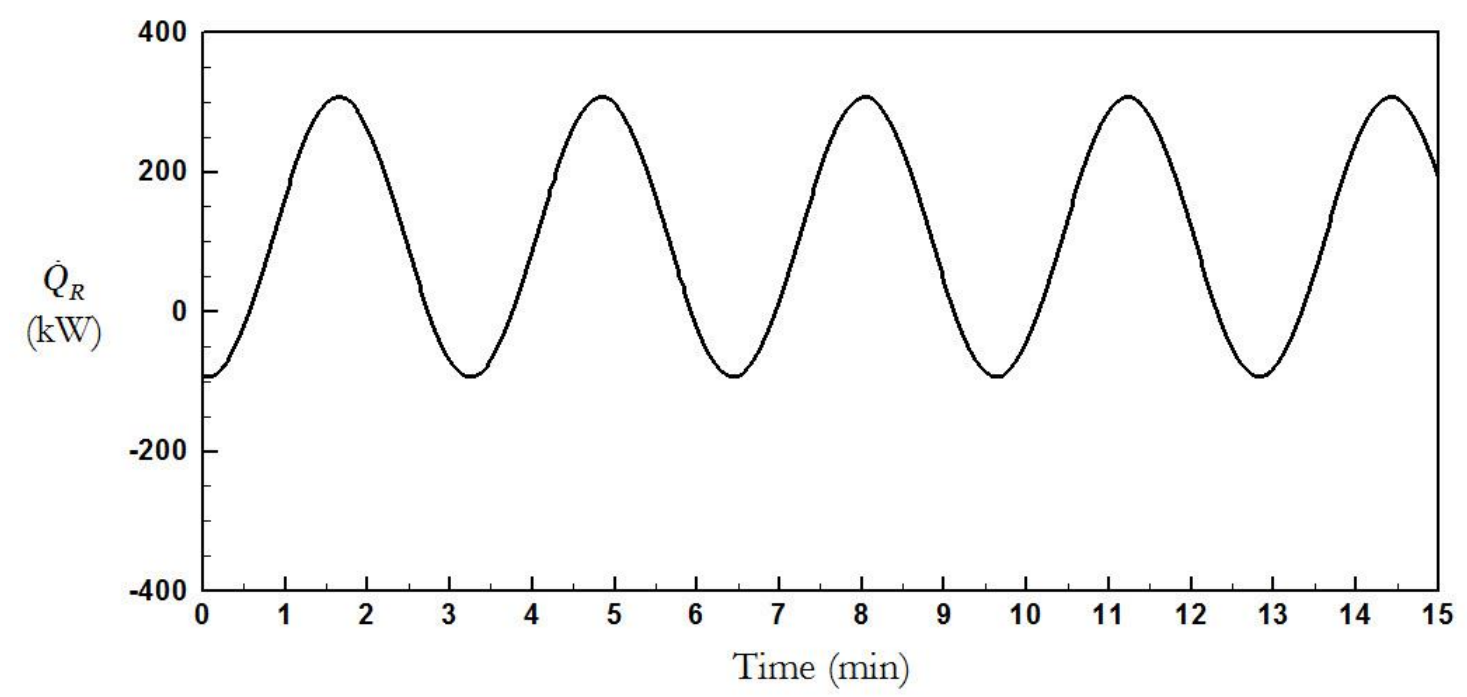

Fig. 13. Variation of the residual heat rate of the absorption chiller with time.

It should be noted that the sign convention of Eq. (6) is based on the heat engine: positive heat input and positive work output. On the other hand, the sign of $\dot{Q}_{R}$ could be positive or negative. Theoretically, $\dot{Q}_{R}$ must be zero due to the absence of any energy interaction to the absorption chiller rather than $\dot{Q}_{C L}$, $\dot{Q}_{R E J}, \dot{Q}_{S T}$ and $\dot{W}_{A C}$. It can be seen from Fig. 13 that $\dot{Q}_{R}$ exhibits the sinusoidal behavior with a fluctuation from $-90.3 \mathrm{~kW}$ to $306.9 \mathrm{~kW}$ which is nearly in phase with COP shown in Fig.12. A Sankey diagram representing the energy balance of the absorption chiller at the average COP is depicted in Fig. 14.

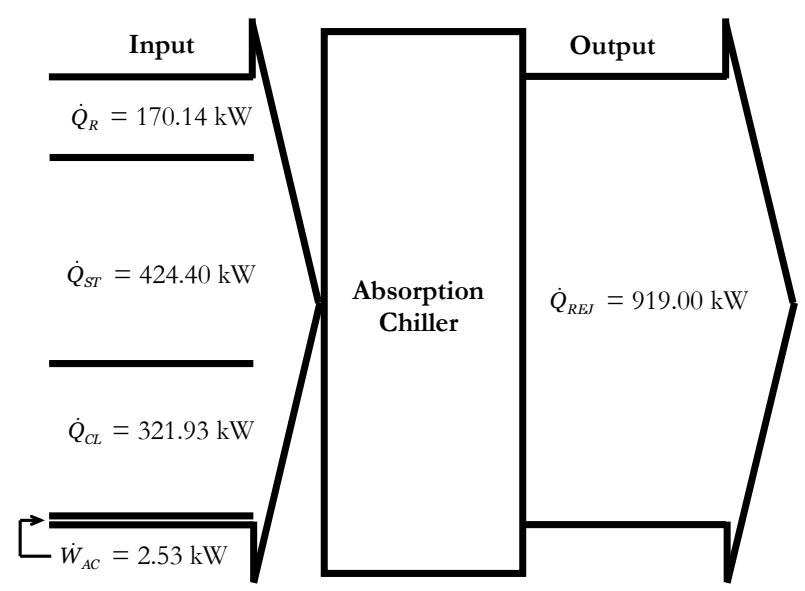

Fig. 14. Sankey diagram of the absorption chiller at the average COP of 0.754 .

At the average COP of $0.754, \dot{Q}_{R}$ is resulted from the heat transfer from the environment into the chiller due to imperfect insulation. Since most part of the working fluid within the absorption refrigeration cycle operates below the ambient temperature, this leads to a positive value of $\dot{Q}_{R}$. It is noted that the magnitude of $\dot{Q}_{R}$ shown in Fig. 14 is approximately 18.5 percent of the total energy input of $919.00 \mathrm{~kW}$.

\section{Conclusion}

The thermal characteristics of an absorption chiller driven by waste steam are investigated in this present paper. The obtained data from the field measurement are analyzed by using a simple average method and by using the sinusoidal regression. The cooling load, the rejected heat rate, the input heat rate from waste steam and the coefficient of performance of the absorption chiller are determined. A study of the residual heat rate based on the energy balance is examined. The result shows the lagging behavior of the cooling load and the rejected heat rate behind the input heat rate from waste steam due to the thermal inertia of the 
absorption chiller. However, the fluctuation of the cooling load and the rejected heat rate is mild compared with that of the input heat rate. The average cooling load, rejected heat rate and input heat rate from waste steam is determined to be $345.78 \mathrm{~kW}, 1033.80 \mathrm{~kW}$, and $572.88 \mathrm{~kW}$, respectively. The fluctuation of the input heat rate from the waste steam can cause COP to vary from 0.296 to 1.524 , with the average value of 0.754. A study of the residual heat rate shows that the fluctuation of the residual heat rate is nearly in phase with that of COP. Based on the energy analysis at the average COP, the residual heat rate is $170.14 \mathrm{~kW}$, caused by the imperfect insulation of the refrigeration system. It is approximated that the residual heat rate is 18.5 percent of the total heat input.

\section{Acknowledgement}

The authors gratefully acknowledge the energy and planning office (EPPO), ministry of energy for the financial support of this project via the demand side management (DSM) bidding program: phase 8.

\section{References}

[1] E. Torrella, D. Sánchez, R Cabello, J. A. Larumbe, and R. Llopis, "On-site real-time evaluation of an air-conditioning direct-fired double-effect absorption chiller," Applied Energy, vol. 86, no. 6, pp. 968975, 2009.

[2] Y. Li, Q. Qiu, and C. Liu, "Operation proposal and efficiency analysis of direct-fired absorption chillers biogas produced in the brewer," in World Renewable Energy Forum (WREF 2012), Denver, CO, May 13-17, 2012, vol. 6, pp. 4713-4720.

[3] S. Ahmed, M. S. A. Mohammed, and S. I. Ul-Haq Gilani, "Exergy analysis of a double-effect parallelflow commercial steam absorption chiller," Journal of Applied Sciences, vol. 12, no. 24, pp. 2580-2585, 2012

[4] H. Yin, D. H. Archer, and M. Qu, "The heat transfer characteristics of a $16 \mathrm{~kW}$ steam driven double effect absorption chiller," in Proceedings of the 2nd International Conference on Energy Sustainability (ES 2008), Jacksonville, FL, August 10-14, 2008, vol. 1, pp. 637-649.

[5] S. M. Jin, L. Y. Chen, and Y. C. Zhu, "Analysis of energy utilizing efficiency in a two-stage $\mathrm{LiBr}-\mathrm{H}_{2} \mathrm{O}$ absorption refrigerator driven by waste heat of flue gas," Journal of Engineering Thermophysics, vol. 31, no. 1, pp. 19-23, 2010.

[6] A. Haywood, J. Sherbeck, P. Phelan, G. Varsamopoulos, and S. K. Gupta, "Thermodynamic feasibility of harvesting data center waste heat to drive an absorption chiller," Energy Conversion and Management, vol. 58, pp. 26-34, 2012.

[7] K. A. Goodheart, S. A. Klein, K. Schultz, J. Lebrun, P. Sarhisia, and J. Kohler, "Economic assessment of low firing temperature absorption chiller systems," ASHRAE Transactions, vol. 108, Part 1, pp. $771-$ 780, 2002.

[8] S. Jeong, B. H. Kang, C. S. Lee, and S. W. Karng, "Computer simulation on dynamic behaviour of a hot water driven absorption chiller," in Proceedings of the International Absorption Heat Pump Conference, January 19-21, 1994, pp. 333-338.

[9] Y. A. Cengel and M. A. Boles, "Refrigeration cycles," in Thermodynamics: an Engineering Approach, 6" edition, Singapore: McGraw Hill, 2007, ch. 11, pp. 647-650.

[10] F. N. Saman and K. Wala-Al-Deen Said, "Modeling the performance of small capacity lithium bromide-water absorption chiller operated by solar energy," in Proceedings of the 31st Intersociety Energy Conversion Engineering Conference: Part 1, Washington, DC, August 11-16, 1996, vol. 3, pp. 1691-1696.

[11] C. D. Erickson, I. Kyung, and P. G. Holdmann, "Geothermal powered absorption chiller for Alaska Ice Hotel," Transactions - Geothermal Resources Council, vol. 29, pp. 57-59, 2005.

[12] Y. Hu, L. Schaefer, and V. Hartkopf, "Detailed energy and exergy analysis for a solar lithium bromide absorption chiller and a conventional electric chiller (R134A)," in International Mechanical Engineering Congress and Exposition (IMECE 2011), Denver, CO, November 11-17, 2011, vol. 4, Parts A and B, pp. 1197-1205.

[13] Y. Hu, L. Schaefer, and V. Hartkopf, "Energy and exergy analysis of integrating compound parabolic collectors (CPC) with lithium bromide ( $\mathrm{Li}-\mathrm{Br})$ absorption chiller for building heating and cooling to achieve net zero buildings," ASHRAE Transactions, vol. 117, no. 2, pp. 174-182, 2011. 
[14] D. Kong, J. Liu, L. Zhang, Z. Fang, and G. Zheng, "Theoretical and experimental analysis of a single stage ammonia-water absorption chiller performance," in International Conference on Energy and Environment Technology (ICEET 2009), Guilin, China, October 16-18, 2009, vol. 1, pp. 475-478.

[15] J. C. Bruno, J. Miquel, and F. Castells, "Optimization of energy plants including water/lithium bromide absorption chillers," International Journal of Energy Research, vol. 24, no. 8, pp. 695-717, 2000.

[16] M. Shekarchiana, M. Moghavvemib, F. Motasemic, and T. M. I. Mahlia "Energy savings and costbenefit analysis of using compression and absorption chillers for air conditioners in Iran," Renewable and Sustainable Energy Reviews, vol. 15, no. 4, pp. 1950-1960, 2011.

[17] "Steam system," in ASHRAE handbook: 2000 HVAC Systems and Equipment, the American Society of Heating, Refrigerating and Air-Conditioning Engineers, Inc., Atlanta, GA, 2000, S10, pp. 10.3.

[18] S. C. Chapra and R. P. Canale, "Fourier Approximation," in Numerical Methods for Engineers, $5^{\text {th }}$ edition, Singapore: McGraw Hill, 2006, ch. 19, pp. 508-512.

[19] C. Borgnakke and R. E. Sonntag, "Appendix B SI units: thermodynamic tables," in Fundamental of Thermodynamics, $7^{\text {th }}$ edition, Singapore: John Wiley \& Sons, 2008, Appendix B, pp. 702-715.

[20] "Absorption cooling, heating, and refrigeration equipment," in ASHRAE handbook: 2002 Refrigeration, the American Society of Heating, Refrigerating and Air-Conditioning Engineers, Inc., Atlanta, GA, 2001, R41, pp. 41.3.

[21] T. M. Mróz, "Thermodynamic and economic performance of the $\mathrm{LiBr}-\mathrm{H}_{2} \mathrm{O}$ single stage absorption water chiller," Applied Thermal Engineering, vol. 26, no. 17-18, pp. 2103-2109, 2006. 